\title{
Urinary Tract Infection in Children with Myelomeningocele
}

\author{
D. G. W. COOPER \\ From the Department of Surgery, Queen Mary's Hospital, Carshalton, Surrey
}

This report deals with the incidence and progress of urinary tract disease in all children with myelomeningocele seen and treated in this Unit between the years 1958 and 1965.

During this period 415 (195 boys, 220 girls) cases were seen and $289(70 \%)$ of these children are still alive. But, though $72 \%$ survived their first birthday, only $50 \%$ of those born more than 5 years ago have survived their fifth birthday, and this latter figure gives a better idea of the real mortality of these cases. Of those over the age of 2 years, $94 \%$ had obvious neurological involvement, of various degrees. Some of the problems associated with the management of the urinary tract in these children are similar to those encountered in other types of paraplegia in which urinary tract disease is the major cause of death (Hackler, Dalton, and Bunts, 1965). The over-all mortality figures from this cause range from 24 to $57 \%$ (Bunts, 1959; Dalton, Hackler, and Bunts, 1965). Will this be the case with myelomeningocele children?

\section{Continence}

Only $13 \%$ of all cases were continent (Table I). Those children who developed hydrocephalus had a higher incidence of neurogenic bladder, and of urinary tract infections, and $93 \%$ had neurogenic bladders compared to the over-all incidence of $87 \%$. Of the continent children, $57 \%$ were boys (Fig. 1) and as there were only $47 \%$ of boys in the whole series this represents a true higher incidence of continence in males. The sex distribution of infection and of upper urinary tract dilatation can also be seen from Table II.

\section{Infection}

The over-all incidence of infection in the children in this series was $37 \%$. Fig. 2 shows that the incidence of urinary tract infection increases with age, and that only $40 \%$ of our cases reach their fifth

Received December 5, 1966.
TABLE I

Neurogenic Bladder in 415 Cases of Spina Bifida

\begin{tabular}{|c|c|c|}
\hline & $\begin{array}{c}\text { Myelo- } \\
\text { meningocele }\end{array}$ & $\begin{array}{l}\text { Myelo- } \\
\text { meningocele } \\
+ \text { Hydro- } \\
\text { cephalus }\end{array}$ \\
\hline $\begin{array}{l}\text { Total No. } \quad . \\
\text { No. with neurogenic bladder } \\
\text { Percentage with neurogenic bladder }\end{array}$ & $\begin{array}{l}95 \\
64 \\
67\end{array}$ & $\begin{array}{r}320 \\
298 \\
93\end{array}$ \\
\hline
\end{tabular}

Over-all incidence of neurogenic bladder $87 \%$.

birthday with uninfected urinary tracts. In those children who die, it is once again seen that there is a gradual increase in the urinary infection rate with the passage of time. There appears to be no age during their first five years of life at which these children are especially liable to develop urinary tract infection.

The level of the spinal lesion had no relation to the incidence of urinary tract infection, but children with encephaloceles were less likely to develop urinary tract infections (Table II).

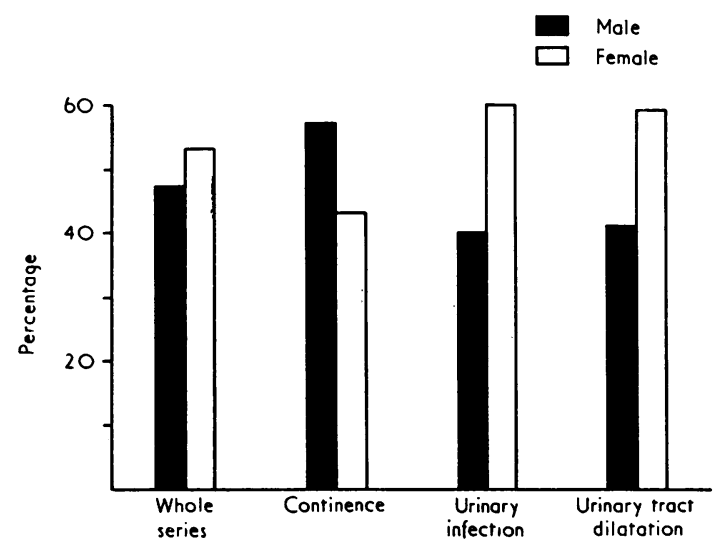

FIG. 1.-Sex distribution of continence, infection, and upper urinary tract dilatation. 
TABLE II

Relation Between Level of Lesion and Number with Urinary Tract Infection

\begin{tabular}{|c|c|c|c|c|c|}
\hline \multicolumn{4}{|c|}{ Level of Lesion } & \multirow{2}{*}{$\begin{array}{c}\begin{array}{c}\text { No. With } \\
\text { Urinary Tract } \\
\text { Infection }\end{array} \\
1 \\
0 \\
4 \\
23 \\
46 \\
22 \\
3\end{array}$} & $\begin{array}{c}\begin{array}{c}\text { Percentage } \\
\text { With Urinary }\end{array} \\
\text { Tract Infection } \\
4\end{array}$ \\
\hline $\begin{array}{l}\text { Occipital } \\
\text { Cervical } \\
\text { Thoracic } \\
\text { Thoracico-lumb } \\
\text { Lumbar } \\
\text { Lumbo-sacral } \\
\text { Sacral .. }\end{array}$ & $\begin{array}{c}\cdots \\
\cdots \\
\text { bar } \\
\cdots \\
\cdots\end{array}$ & $\begin{array}{l}\cdots \\
\cdots \\
\cdots \\
\cdots \\
\cdots\end{array}$ & $\begin{array}{l}\cdots \\
\cdots \\
\cdots \\
\cdots \\
\cdots\end{array}$ & & $\begin{array}{l}4 \\
28 \\
35 \\
41 \\
36 \\
21\end{array}$ \\
\hline
\end{tabular}

Over-all infection rate $37 \%$.

The average age at death of those dying with urinary tract infection is higher than in those dying without this complication (15.5 months compared with 4.9 months in the uninfected group).

TABLE III

Percentage of Cases Infected By Different Organisms

\begin{tabular}{|c|c|c|c|}
\hline Organism & $\begin{array}{c}\text { Percentage } \\
\text { of Whole } \\
\text { Group } \\
(154)\end{array}$ & $\begin{array}{c}\text { Percentage } \\
\text { of Iatrogenic } \\
\text { Infections } \\
\text { After } \\
\text { Cystography } \\
\text { (8) }\end{array}$ & $\begin{array}{c}\text { Percentage } \\
\text { of } \\
\text { Out-patient } \\
\text { Cases } \\
\text { (22) }\end{array}$ \\
\hline $\begin{array}{l}\begin{array}{l}\text { Proteus spp. } \\
\text { Esch. coli }\end{array} \\
\text { Ps. pyocyanea } \\
\text { Kleb. aerogenes... } \\
\text { Esch. coli/Proteus } \\
\text { Proteus/Ps. pyocyanea } \\
\text { Staph./Proteus } \\
\text { Others .. }\end{array}$ & $\begin{array}{r}47 \\
30 \\
21 \\
12 \\
15 \\
2 \\
17\end{array}$ & $\begin{array}{l}75 \\
25 \\
50 \\
12 \\
= \\
=\end{array}$ & $\begin{array}{r}50 \\
19 \\
9 \\
4 \\
4 \\
4 \\
4 \\
-\end{array}$ \\
\hline
\end{tabular}

Table III shows the organisms involved in the urinary tract infections investigated. The pattern of organisms in the whole group has been compared with that found in a routine out-patient check on every child seen with spina bifida. In both these groups proteus is the commonest infecting organism. It is possible that there is a significant reduction in infection by $P$ s. pyocyanea in non-hospitalized cases. The iatrogenic group consists of cases where infection of the urinary tract has followed the catheterization necessary for carrying out cystographic examinations. Once again, proteus is the commonest organism involved, but the numbers are small. Urinary tract infections in these children commonly begin with a single organism, but the chances of infection with multiple organisms increase with age. As one infection follows another, the organisms tend to change (Table IV).

All children with spina bifida cared for at home and attending as out-patients had their urine tested

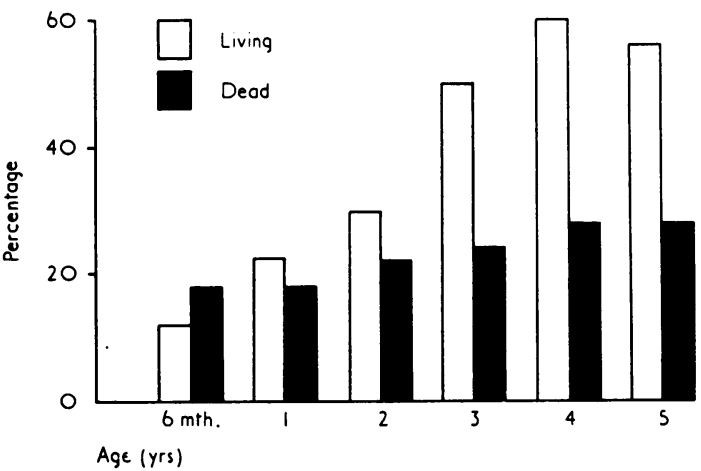

FIG. 2.-Urinary infection rate in different age-groups.

over a nine-month period. Infection was present in only $26 \%$, as compared to the over-all figure of $37 \%$.

\section{Dilatation of Upper Urinary Tract}

Dilatation of the upper urinary tract was observed in $33 \%$ of the children with urinary tract infection $(51 / 154)$, whereas only $15 \%$ of those in the uninfected group showed these changes $(39 / 261)$. The over-all number showing dilatation of the upper urinary tract is $22 \%$.

In those children who developed dilatation of the upper urinary tract, the changes were unilateral in $37 \%(34 / 91)$.

Fig. 3 shows that the over-all incidence of upper urinary tract dilatation will level off at $30 \%$ in spite of more intensive investigation of these children. The incidence of upper urinary tract dilatation increases with age in a similar manner to that of urinary infection.

In this series, dilatation of the upper urinary tract was more common in girls (see Fig. 1). Table V shows that children with a thoraco-lumbar lesion are more likely to develop dilatation of the upper urinary tract than children with other lesions. In the light of recent work on the innervation of the

TABLE IV

Incidence of Multiple Infection

\begin{tabular}{|c|c|c|c|c|c|}
\hline & \multicolumn{4}{|c|}{ Age (yr.) } & $\frac{\begin{array}{c}\text { Percentage With } \\
\text { Multiple Organisms }\end{array}}{47}$ \\
\hline $\begin{array}{l}1 \\
2 \\
3 \\
4 \\
5 \\
6 \\
7 \\
8\end{array}$ & $\begin{array}{l}\cdots \\
\cdots \\
\cdots \\
\cdots \\
\cdots\end{array}$ & $\begin{array}{l}\cdots \\
\cdots \\
\cdots \\
\cdots \\
\cdots\end{array}$ & $\begin{array}{l}\ldots \\
\cdots \\
\cdots \\
\cdots \\
\cdots\end{array}$ & $\begin{array}{l}\ldots \\
\cdots \\
\cdots \\
\cdots \\
\cdots \\
\cdots \\
\cdots\end{array}$ & $\begin{array}{l}47 \\
50 \\
59 \\
62 \\
64 \\
77 \\
87 \\
91\end{array}$ \\
\hline
\end{tabular}




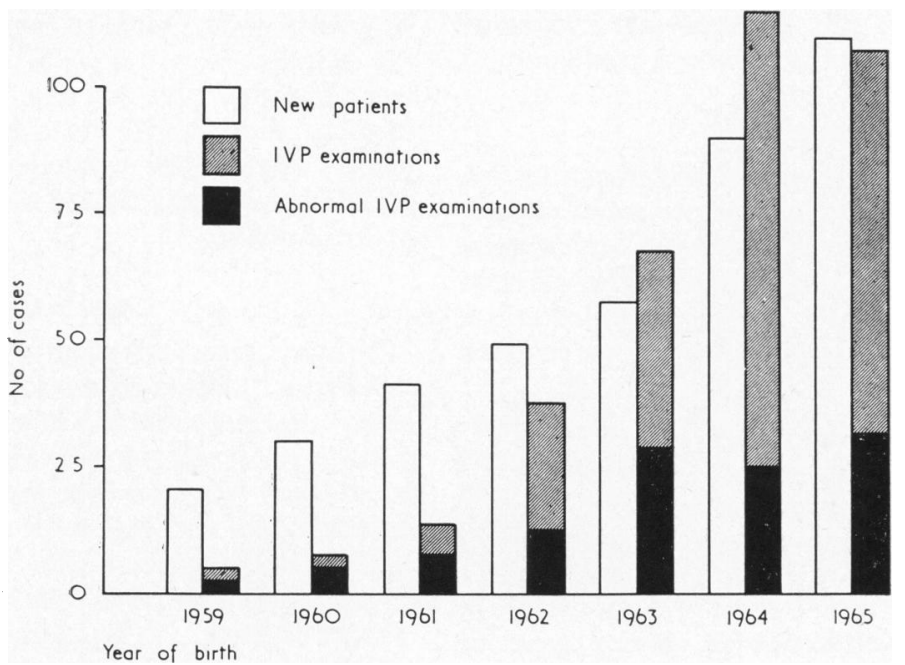

Fig. 3.-Number of patients per year, normal and abnormal findings at intravenous pyelography.

bladder (Tanagho, Hutch, Meyers, and Rambo, 1965; Tanagho, Miller, Meyers, and Corbett, 1966; Tanagho and Smith, 1966), it seems that this difference may be due to the involvement of the sympathetic outflow in children with the higher lesion. Bladder pressures in all phases of micturition tend to be lower in girls (Nunn, 1965), and it is hard to accept the higher prevalence in girls of dilatation in the upper urinary tract as being due to mechanical obstruction. Many of these cases of upper urinary tract dilatation may be secondary to infection. This conclusion is based on the finding of a high incidence of infection, incontinence, and urinary tract dilatation in girls (see Fig. 1).

It has been shown that, in dogs, infection may cause reflux without any change in the haemodynamics of the bladder (Schoenberg, Beisswanger, Howard, Klingenmaier, Walter, and Murphy, 1964).

\section{TABLE V}

Relation Between Level of Lesion and Back Pressure Changes

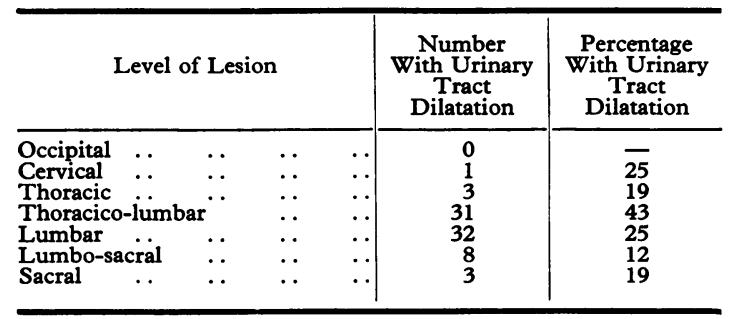

It has also been shown experimentally that kidneys with chronic pyelonephritis develop hydronephrosis more rapidly in the presence of urinary tract obstruction (Nicolai, 1964). While the main factor involved in these cases of upper urinary tract dilatation is undoubtedly paralytic involvement of the bladder, the higher incidence of infection in girls may add an important inflammatory element to the cause of reflux.

Urinary tract dilatation did not, in this series, significantly affect the mortality rate during the first five years of life. Over the five-year period of this study the mortality rate in children with dilatation of the upper urinary tract was $25 \%$, and this is little different from the over-all mortality rate in children without these changes (29\%). A study of the cause of death in over 1000 treated cases of myelomeningocele confirms the fact that deaths from urinary tract disease are spread equally over the first five years of life.

\section{Reflux}

This is classically demonstrated by means of cystographic radiological techniques. However, the hazards of introducing infection into a previously sterile, but almost certainly abnormal urinary tract, during catheterization have been frequently emphasized, and some believe that on these grounds this investigation is not justified in children with spina bifida. We have carried out this investigation on only 55 children: of those coming uninfected to cystography, $42 \%$ developed a urinary tract infection as a direct result of this examination; in only 
$20 \%$ of these cases was an abnormal cystogram associated with a normal intravenous pyelogram.

\section{Management}

All children with confirmed urinary tract infection have received intermittent symptomatic chemotherapy. It has not been our policy in any of these patients to use long-term prophylactic chemotherapy. However, a few patients, with infections which relapsed on cessation of therapy, have received continuous chemotherapy for long periods.

Dilatation of the upper urinary tract, if progressive, has been treated surgically. 24 children have had urinary diversion procedures, and 21 operations have been carried out on the bladder neck.

\section{Discussion}

A group of 415 children with varying types of spina bifida have been closely followed and treated throughout their lives by this Unit. Our figures give a more accurate idea of the incidence of disease in these children as a whole than do figures from urological centres.

Although we would expect to see similarities between the urological problems encountered in these children and those encountered in the management of paraplegia of other origin, this does not appear to be the case. No cases of amyloidosis have been found in any of our necropsies $(80 \%$ of all those who have died have had a post-mortem examination), whereas amyloidosis has been found in $43-85 \%$ of adult paraplegics who die, and has even been incriminated as the cause of renal failure. Stone formation has also been notably absent in our cases. It is possible that the greater flow of urine in children protects them from stone formation, and they have greater resistance than adults to amyloid changes in the presence of chronic sepsis.

Urinary tract disease does not seem to contribute greatly to the mortality during the first five years of life and $40 \%$ will survive this period without serious urinary tract infection. We found dilatation of the upper urinary tract in only $22 \%$ of our cases, and a much lower rate of infection than that reported by other workers. These low figures are not due to inadequate investigation. It is possible that many of the other recorded series are either of cases relatively untreated by our present standards, or of selected children who already have urological problems. It thus seems that if a large enough group of children with spina bifida are studied, the prognosis with regards to their urinary tract during the first five years of life is much better than has been thought. By the time they reach their fifth birthday a third will show dilatation of the upper urinary tract, a third will have chronic infection but no dilatation, and a third will show neither but will be incontinent.

\section{Conclusions}

Urinary tract infection occurs in $60 \%$ of all children with spina bifida during the first five years of life, and is commoner in girls. It is not related to the level of the spinal lesion. It is less common in children who are out-patients. Urinary tract infection does not seem to be a major cause of death in the first five years of life.

Upper urinary tract dilatation occurs in about $30 \%$ of all cases. It is commoner in girls; and with spinal lesions affecting the thoracic region. Infection of the urinary tract probably contributes to the causation of dilatation of the upper urinary tract.

Although evidence of urinary tract infection was noted on many occasions at necropsy, in no case was there evidence of amyloid disease, contrasting with the great frequency with which amyloid disease is observed in other types of paraplegia.

Following cystography, infection developed in $42 \%$ of cases which were previously uninfected. Abnormality not previously shown by intravenous pyelography was only demonstrated by cystography in $20 \%$ of cases.

I would like to thank $\mathrm{Mr}$. H. B. Eckstein and $\mathrm{Mr}$. D. M. Forrest for permission to study their cases.

REFERENCES

Bunts, R. C. (1959). Preservation of renal function in the paraplegic. F. Urol. (Baltimore), 81, 720.

Dalton, J. J., Jr., Hackler, R. H., and Bunts, R. C. (1965). Amyloidosis in the paraplegic. ibid., 93, 553.

Hackler, R. H., Dalton, J. J., Jr., and Bunts, R. C. (1965). Changing concepts in the preservation of renal function in the paraplegic. ibid., 94, 107.

Nicolai, C. H. (1964). Role of chronic pyelonephritis in the production of experimental hydronephrosis. ibid., 92, 347.

Nunn, I. N. (1965). Bladder neck obstruction in children. ibid., 93, 693.

Schoenberg, H. W., Beisswanger, P., Howard, W. J., Klingenmaier, H., Walter, C. F., and Murphy, J. J. (1964). Effect of lower urinary tract infection upon ureteral function. ibid., 92, 107.

Tanagho, E. A., Hutch, J. A., Meyers, F. H., and Rambo, O. N., Jr. (1965). Primary vesicoureteral reflux. ibid., 93, 165.

-, Miller, E. R., Meyers, F. H., and Corbett, R. K. (1966). Observations on the dynamics of the bladder neck. Brit. $\mathcal{F}$. Urol., 38, 72.

-, and Smith, D. R. (1966). The anatomy and function of the bladder neck. ibid., 38, 54 . 